\title{
EFFECT OF DIFFERENT IMMERSION SOLUTIONS ON COLOR STABILITY OF ONE BULK-FILL RESIN COMPOSITE AND TWO TYPES OF CAD/CAM CERAMICS
}

\author{
Sara H. Younis *, Rasha H Afifi * and Mostafa Aboushahba **
}

\begin{abstract}
Objective: This study aimed to evaluate the effect of immersion solutions on color stability of two thicknesses of bulk-fill composite and two CAD/CAM ceramics.

Materials and methods: One Bulk-fill (X-tra fil) composite ( 2 and $4 \mathrm{~mm}$ increment) and two types of CAD/CAM ceramics (ViteEnamic and VitablocsMark II) were used. Forty two composite specimens were prepared with two different thicknesses, also twenty-one specimens of each ceramic material ( $2 \mathrm{~mm}$ in thickness) were prepared for color change evaluation after immersion in distilled water, cola and coffee. Kruskal-Wallis test was used to compare between materials as well as to compare between immersion solutions. Dunn's test was used for pair-wise comparisons when Kruskal-Wallis test is significant. The significance level was set at $\mathrm{P} \leq 0.05$.
\end{abstract}

Results: In distilled water there was no statistically significant difference between values of composite and vitaenamic, both were statistically higher than vitamark II, with cola X-trafil $2 \mathrm{~mm}$ showed the statistically significantly highest median $\Delta \mathrm{E}, 4 \mathrm{~mm}$ showed statistically significantly lower median value, there was no statistically significant difference between ceramics; both showed the statistically significantly lowest median $\Delta \mathrm{E}$ values. With coffee there was no statistically significant difference between X-trafils; both showed the statistically significantly highest median $\Delta \mathrm{E}$ values, and no statistically significant difference occurred between ceramics; both showed the statistically significantly lowest median $\Delta \mathrm{E}$ values.

Conclusion: Composites are unable to retain the color they possessed after storage, but the color of both types of ceramic is stable even after immersion and storage in distilled water, cola and coffee.

KEYWORDS: Resin composite, bulkfill resin composite, beverages, color stability, Hybrid ceramic, Feldspathic Ceramic, staining.

\footnotetext{
* Lecturer, Conservative Dentistry Department, Faculty of Oral and Dental Medicine, Future University in Egypt, Cairo, Egypt.
} ** Lecturer, Fixed prosthodontic Department, Faculty of Oral and Dental Medicine, Future University in Egypt, Cairo, Egypt. 


\section{INTRODUCTION}

Color match and stability of dental materials affect the success and failure of esthetic restorations. Clinically, the success of any restorative material is strongly influenced by its intrinsic characteristics, and the oral environment. The oral environment is a complex, aqueous environment with saliva, and $\mathrm{pH}$ fluctuations due to consumption of different food and drinks. ${ }^{1}$

Color stability of resin composite is a challenge as color change occurs due to various factors some are extrinsic and the others are intrinsic. Extrinsic discoloration occurs on the superficial layer due to water absorption, surface roughness, smoking, and diet. Intrinsic discoloration on the other hand occurs as a result of a reaction within the material. ${ }^{2}$

Bulk-fill resin composite materials can be packed in $4 \mathrm{~mm}$ single increment, then cured properly without influencing their polymerization shrinkage or degree of conversion, but many clinicians need to further investigate the depth of cure and the mechanical properties to be able to successfully use them clinically. ${ }^{2}$

VITA ENAMIC is a hybrid dental ceramic with a dual-network structure that combines the benefits of resinous and ceramic materials. It has a dominant porous sintered feldspathic ceramic network as Vitablocs Mark II but VITAENAMIC is strengthened by a methacrylate polymeric network, forming a polymer infiltrated-ceramic-network (PICN). Color matching of VITA ENAMIC is identical to natural teeth, it has high flexural strength, elasticity similar to that of dentin, high bond strength due to their fine ceramic structure and the polymer network, and better internal and marginal adaptation than feldspathic ceramics. ${ }^{(1,3)}$

Coffee and cola are of the major contributors to staining of dental composites, the degree of staining vary according to many factors as the material type, filler content, finishing and polishing, and the type of the extrinsic colorants. ${ }^{4}$ That is why the effect of consumption of cola and coffee on the clinical performance of different esthetic restorative materials regarding color stability is an issue that needs attention.

So, this study was designed to investigate the effect of storage, in different immersion solutions, on the color stability of two thicknesses of one bulkfill resin composite and two types of CAD/CAM ceramic blocks.

\section{MATERIALS AND METHODS}

\section{Materials}

One Universal light cured hybrid bulk-fill resin composite (X-tra fil) with two different thicknesses 2 and $4 \mathrm{~mm}$ [groups 1 and 2 respectively], together with two types of CAD/CAM ceramic blocks were used in the present investigation, one polymer infiltrated-ceramic-network (Vita Enamic) [Group 3] and one feldspathic ceramic (Vitablocs Mark II) [Group 4], both by (Vita Zahnfabrik, Bad Sackingen, Germany). Characteristics of the materials are presented in Tables 1 and 2.

TABLE (1) Resin composite

\begin{tabular}{|l|l|l|l|l|l|}
\hline Material & \multicolumn{1}{|c|}{ Type } & \multicolumn{2}{|c|}{ Composition } & Filler amount, wt\%, vol \% & $\begin{array}{l}\text { Manufacturer } \\
\text { and Lot\# }\end{array}$ \\
\hline $\begin{array}{l}\text { X-trafil } \\
\text { (bulk-fill) }\end{array}$ & $\begin{array}{l}\text { Micro- } \\
\text { hybrid }\end{array}$ & $\begin{array}{l}\text { Methacrylate matrix } \\
\text { (Bis-GMA, UDMA, } \\
\text { TEGDMA) }\end{array}$ & $\begin{array}{l}\text { Barium-boron- } \\
\text { alumino-silicate glass } \\
(2-3 \mu \mathrm{m})\end{array}$ & $\begin{array}{l}86 \% \text { by weight inorganic } \\
\text { filler } \\
(70.1 \% \text { by volume })\end{array}$ & $\begin{array}{l}\text { Voco, Guxhaven, } \\
\text { Germany. } \\
1343523\end{array}$ \\
\hline
\end{tabular}


TABLE (2) CAD/CAM ceramic blocks.

\begin{tabular}{|c|c|c|c|c|}
\hline $\begin{array}{c}\text { Lot } \\
\text { Number }\end{array}$ & Block dimensions & Manufacturer & Composition & $\begin{array}{c}\text { CAD/CAM ceramic } \\
\text { block }\end{array}$ \\
\hline 48720 & $114(12 \times 14 \times 18)$ & $\begin{array}{c}\text { Vita Zahnfabrik, } \\
\text { Bad Sackingen, } \\
\text { Germany }\end{array}$ & $\begin{array}{c}\text { Fine-structure feldspar ceramic } 86 \\
\text { wt\% Methacrylate polymer } 14 \text { wt } \% \\
(\text { TEGDMA 33 wt } \% \text {, UDMA 66 wt } \%)\end{array}$ & $\begin{array}{c}\text { Vita Enamic (En) } \\
\text { (Polymer-infiltrated- } \\
\text { ceramic network) }\end{array}$ \\
\hline 31710 & \multirow{2}{*}{$114(12 \times 14 \times 18)$} & $\begin{array}{c}\text { Vita Zahnfabrik, } \\
\text { Bad Sackingen, } \\
\text { Germany }\end{array}$ & $\begin{array}{c}\text { Fine-particle feldspar ceramic mill } \\
\text { block Al2O3 - SiO2 - Na 2O-K 2O }\end{array}$ & $\begin{array}{c}\text { Vitablocs Mark II (Vm) } \\
\text { (Feldspathic ceramic) }\end{array}$ \\
\hline
\end{tabular}

\section{Methods}

Fourty-two bulk-fill resin composite specimens were prepared for this study with two different thicknesses ( $2 \mathrm{~mm}$ and $4 \mathrm{~mm}$ thickness) $(\mathrm{n}=21)$.

All specimens with the two different thicknesses ( $2 \mathrm{~mm}$ and $4 \mathrm{~mm}$ thickness) were prepared using a polyethylene mold, 2 glass slides and 2 Mylar strips. After applying the resin composite material in the mold, a Mylar strip was applied on top and it was pressed with a glass slide to obtain flat surface. The glass slide was then removed and the specimens were cured from the top surface only for 40 seconds using a LED light curing Unit with an output $\geq 800$ $\mathrm{Mw} / \mathrm{cm}^{2}$. The light curing tip was performed at zero distance from the Mylar strip. The power density of the light curing unit was regularly checked with a radiometer. After demolding, the top surfaces of the specimens were identified with a permanent mark. All specimens were then stored in distilled water for 24 hours in black containers.

The CAD/CAM blocks of the two materials were sectioned using a slow speed diamond saw (Buehler, IL, USA) under copious amount of water. Twenty-one specimens of each material $(n=21) ; 2$ $\mathrm{mm}$ in thickness, were prepared for color change assessment.

Baseline color of all specimens was measured and recorded using a digital portable spectrophotometer (Vita Easyshade Advance, Vita Zahnfabrik, Bad Säckingen, Germany) with CIELab technology by the same operator to obtain the [pre immersion spectrophotometric value $(\Delta \mathrm{E} 1)]$, which served as a reference to measure color change after storage in the immersion solutions [post immersion spectrophotometric value $(\Delta \mathrm{E} 2)]^{4}$.

By the same operator, the color change values were recorded using the same digital portable spectrophotometer. Three measurements were taken with the active point of the spectrophotometer in the center of each specimen. Then the spectrophotometer automatically averaged the three readings, and this average reading was recorded and used for statistical analysis. ${ }^{5}$

\section{Immersion solutions}

Specimens of each group ( $\mathrm{n}=21$ ) were randomly divided into three subgroups according to the immersion solutions used $(n=7)$. Two different solutions served as the staining solutions in this study: $50 \mathrm{ml}$ of Nescafé soluble coffee (Nestlé, Vevey, Switzerland), $50 \mathrm{ml}$ Coca Cola soda (Coca cola Company), together with $50 \mathrm{ml}$ distilled water that served as the third solution (control) and all specimens were stored in black containers for 28 days. ${ }^{1}$

The coffee was prepared by adding $50 \mathrm{ml}$ of boiling water to one spoonful of coffee according to manufacturer's recommendations (approximately $10 \mathrm{~g} / 50 \mathrm{~mL}$ ).

Every day all the immersion solutions were renewed for all specimens; the specimens were 
washed with distilled water and dried with absorbent paper before the new immersion for 28 days. $^{6}$ At the end of the 28 days the effect of the immersion solutions on the color of the tested materials was examined through obtaining the post immersion spectrophotometric values $(\Delta \mathrm{E} 2)$.

According to the $\mathrm{L}^{*}, \mathrm{a}^{*}$ and $\mathrm{b}^{*}$ values, the color change was calculated ${ }^{7}$ as:

$$
\Delta \mathrm{E}^{*}=\left[\left(\Delta \mathrm{L}^{*}\right)^{2}+\left(\Delta \mathrm{a}^{*}\right)^{2}+\left(\Delta \mathrm{b}^{*}\right)^{2}\right]^{1 / 2}
$$

\section{Statistical Analysis}

Numerical data were explored for normality by checking the distribution of data and using tests of normality (Kolmogorov-Smirnov and ShapiroWilk tests). Color change $(\Delta \mathrm{E})$ data showed nonnormal (non-parametric) distribution. Data were presented as mean, standard deviation (SD), median and range values. Kruskal-Wallis test was used to compare between materials as well as to compare between immersion solutions. Dunn's test was used for pair-wise comparisons when KruskalWallis test is significant. The significance level was set at $\mathrm{P} \leq 0.05$. Statistical analysis was performed with IBM SPSS Statistics for Windows, Version 23.0. Armonk, NY: IBM Corp.

\section{RESULTS:}

Descriptive statistics of $\Delta \mathrm{E}$ values are presented in Tables (3), (4) and (5).

Comparison between immersion solutions: (Table 4)

- With X-tra fil $2 \mathrm{~mm}$; there was a statistically significant difference between immersion media $(P$-value $=0.002$, Effect size $=0.875)$. Pairwise comparisons between the media revealed that coffee showed the statistically significantly highest median $\Delta \mathrm{E}$. Cola showed statistically significantly lower median value. Distilled water showed the statistically significantly lowest median $\Delta \mathrm{E}$.
- With X-tra fil $4 \mathrm{~mm}$; there was a statistically significant difference between immersion media $(P$-value $=0.002$, Effect size $=0.875)$. Pairwise comparisons between the media revealed that coffee showed the statistically significantly highest median $\Delta \mathrm{E}$. Cola showed statistically significantly lower median value. Distilled water showed the statistically significantly lowest median $\Delta \mathrm{E}$.

- With Vita Enamic; there was a statistically significant difference between immersion media $(P$-value $=0.048$, Effect size $=0.340)$. Pair-wise comparisons between the media revealed that there was no statistically significant difference between Cola and coffee; both showed statistically significantly higher median $\Delta \mathrm{E}$ than distilled water.

- With Vita Mark II; there was a statistically significant difference between immersion media $(P$-value $=0.002$, Effect size $=0.884)$. Pairwise comparisons between the media revealed that Cola showed the statistically significantly highest median $\Delta \mathrm{E}$. Coffee showed statistically significantly lower median value. Distilled water showed the statistically significantly lowest median $\Delta \mathrm{E}$.

\section{Comparison between materials: (Table 5)}

- After immersion in distilled water: there was a statistically significant difference between the materials $(P$-value $=0.007$, Effect size $=$ 0.572). Pair-wise comparisons between the materials revealed that there was no statistically significant difference between X-tra fil $2 \mathrm{~mm}$, $\mathrm{X}$-tra fil $4 \mathrm{~mm}$ and Vita Enamic; all showed statistically significantly higher median $\Delta \mathrm{E}$ than Vita Mark II.

- After immersion in Cola; there was a statistically significant difference between the materials $(P$-value $<0.001$, Effect size $=0.932)$. Pair-wise comparisons between the materials 
revealed that X-tra fil $2 \mathrm{~mm}$ showed the statistically significantly highest median $\Delta \mathrm{E}$. $\mathrm{X}$-tra fil $4 \mathrm{~mm}$ showed statistically significantly lower median value. There was no statistically significant difference between Vita Enamic and Vita Mark II; both showed the statistically significantly lowest median $\Delta \mathrm{E}$ values.

- After immersion in coffee; there was a statistically significant difference between the materials $(P$-value $=0.001$, Effect size $=$ 0.850). Pair-wise comparisons between the materials revealed that there was no statistically significant difference between X-tra fil $2 \mathrm{~mm}$ and X-tra fil $4 \mathrm{~mm}$ groups; both showed the statistically significantly highest median $\Delta \mathrm{E}$ values. There was no statistically significant difference between Vita Enamic and Vita Mark II; both showed the statistically significantly lowest median $\Delta \mathrm{E}$ values.

TABLE (3) Descriptive statistics of color change $(\Delta \mathrm{E})$ values

\begin{tabular}{|l|l|c|c|c|c|c|}
\hline \multirow{4}{*}{ Material } & $\begin{array}{l}\text { Immersion } \\
\text { solution }\end{array}$ & Mean & SD & & \multicolumn{2}{|c|}{ Range } \\
\cline { 3 - 7 } X-tra fil 2mm & Distilled water & 2.68 & 2.69 & 1.97 & 0.43 & 7.35 \\
\cline { 2 - 7 } & Cola & 11.21 & 0.83 & 11.07 & 10.4 & 12.41 \\
\cline { 2 - 7 } & Coffee & 19.35 & 4.27 & 18.19 & 16.47 & 26.84 \\
\hline \multirow{5}{*}{ X-tra fil 4mm } & Distilled water & 1.62 & 0.3 & 1.74 & 1.17 & 1.88 \\
\cline { 2 - 7 } & Cola & 4.44 & 0.45 & 4.29 & 4.01 & 5.14 \\
\cline { 2 - 7 } & Coffee & 15.47 & 2.63 & 14.93 & 12.13 & 18.38 \\
\hline \multirow{5}{*}{ Vita Enamic } & Distilled water & 1.35 & 0.27 & 1.23 & 1.03 & 1.63 \\
\cline { 2 - 7 } & Cola & 1.54 & 0.55 & 1.86 & 0.94 & 2.08 \\
\cline { 2 - 7 } & Coffee & 2.03 & 0.28 & 2.17 & 1.73 & 2.33 \\
\hline & Distilled water & 0.13 & 0.09 & 0.08 & 0.06 & 0.28 \\
\cline { 2 - 7 } & Cola & 2.53 & 0.42 & 2.7 & 2.1 & 3.07 \\
\cline { 2 - 7 } & Coffee & 1.06 & 0.07 & 1.1 & 0.98 & 1.12 \\
\hline
\end{tabular}

TABLE (4): The median, range values and results of Kruskal-Wallis test for comparison between $\Delta \mathrm{E}$ values of different immersion solutions.

\begin{tabular}{|c|c|c|c|c|c|c|c|c|c|c|c|c|}
\hline \multirow{2}{*}{$\begin{array}{l}\text { Material } \\
\text { Immersion } \\
\text { solution }\end{array}$} & \multicolumn{3}{|c|}{$X$-tra fil $2 \mathrm{~mm}$} & \multicolumn{3}{|c|}{ X-tra fil $4 \mathrm{~mm}$} & \multicolumn{3}{|c|}{ Vita Enamic } & \multicolumn{3}{|c|}{ Vita Mark II } \\
\hline & Median & Min. & Max. & Median & Min. & Max. & Median & Min. & Max. & Median & Min. & Max. \\
\hline Distilled water & $1.97^{\mathrm{C}}$ & 0.43 & 7.35 & $1.74^{\mathrm{C}}$ & 1.17 & 1.88 & $1.23^{\mathrm{B}}$ & 1.03 & 1.63 & $0.08^{\mathrm{C}}$ & 0.06 & 0.28 \\
\hline Cola & $11.07^{\mathrm{B}}$ & 10.4 & 12.41 & $4.29^{\mathrm{B}}$ & 4.01 & 5.14 & $1.86^{\mathrm{A}}$ & 0.94 & 2.08 & $2.7^{\mathrm{A}}$ & 2.1 & 3.07 \\
\hline Coffee & $18.19^{\mathrm{A}}$ & 16.47 & 26.84 & $14.93^{\mathrm{A}}$ & 12.13 & 18.38 & $2.17^{\mathrm{A}}$ & 1.73 & 2.33 & $1.1^{\mathrm{B}}$ & 0.98 & 1.12 \\
\hline$P$-value & \multicolumn{3}{|c|}{$0.002 *$} & \multicolumn{3}{|c|}{$0.002 *$} & \multicolumn{3}{|c|}{$0.048^{*}$} & \multicolumn{3}{|c|}{$0.002 *$} \\
\hline $\begin{array}{c}\text { Effect size } \\
\text { (Eta squared }\end{array}$ & \multicolumn{3}{|c|}{0.875} & \multicolumn{3}{|c|}{0.875} & \multicolumn{3}{|c|}{0.340} & \multicolumn{3}{|c|}{0.884} \\
\hline
\end{tabular}

*: Significant at $P \leq 0.05$, Different superscripts in the same column indicate statistically significant difference between immersion medium. 
TABLE (5): The median, range values and results of Kruskal-Wallis test for comparison between $\Delta \mathrm{E}$ values of different materials.

\begin{tabular}{|c|c|c|c|c|c|c|c|c|c|c|c|c|c|c|}
\hline \multirow{2}{*}{$\begin{array}{l}\text { Material } \\
\text { Immersion } \\
\text { solution }\end{array}$} & \multicolumn{3}{|c|}{ X-tra fil $2 \mathrm{~mm}$} & \multicolumn{3}{|c|}{ X-tra fil $4 \mathrm{~mm}$} & \multicolumn{3}{|c|}{ Vita Enamic } & \multicolumn{3}{|c|}{ Vita Mark II } & \multirow{2}{*}{ P-value } & \multirow{2}{*}{$\begin{array}{c}\text { Effect } \\
\text { size (Eta } \\
\text { squared) }\end{array}$} \\
\hline & Median & Min. & Max. & Median & Min. & Max. & Median & Min. & Max. & Median & Min. & Max. & & \\
\hline $\begin{array}{l}\text { Distilled } \\
\text { water }\end{array}$ & $1.97^{\mathrm{A}}$ & 0.43 & 7.35 & $1.74^{\mathrm{A}}$ & 1.17 & 1.88 & $1.23^{\mathrm{A}}$ & 1.03 & 1.63 & $0.08^{\mathrm{B}}$ & 0.06 & 0.28 & $0.007 *$ & 0.572 \\
\hline Cola & $11.07^{\mathrm{A}}$ & 10.4 & 12.41 & $4.29^{\mathrm{B}}$ & 4.01 & 5.14 & $1.86^{\mathrm{C}}$ & 0.94 & 2.08 & $2.7^{\mathrm{C}}$ & 2.1 & 3.07 & $<0.001 *$ & 0.932 \\
\hline Coffee & $18.19^{\mathrm{A}}$ & 16.47 & 26.84 & $14.93^{\mathrm{A}}$ & 12.13 & 18.38 & $2.17^{\mathrm{B}}$ & 1.73 & 2.33 & $1.1^{\mathrm{B}}$ & 0.98 & 1.12 & $0.001 *$ & 0.850 \\
\hline
\end{tabular}

*: Significant at $P \leq 0.05$, Different superscripts in the same row indicate statistically significant difference between materials

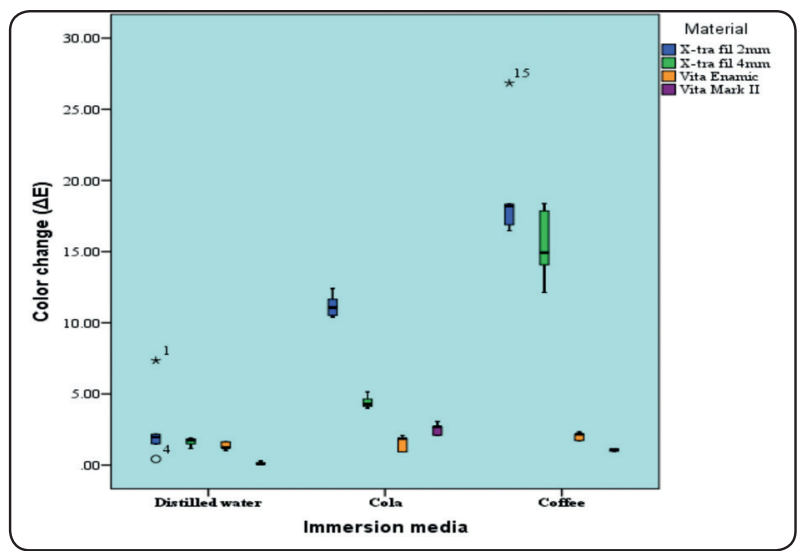

Fig. (1). Box plot representing median and range values for $\Delta \mathrm{E}$ of the different materials with different immersion media (Stars and circle represent outliers)

\section{DISCUSSION}

In the present study the effect of distilled water, cola and coffee on the color stability of one bulk-fill resin composite (with different thicknesses) and two ceramics (polymer infiltrated-ceramic-network and a feldspathic ceramic) was investigated. Liquids as water, cola and coffee are frequently ingested in the oral cavity and so come in contact with dental restorations present in the oral environment, so these solutions represented the immersion storage solutions used in this study. It has been previously concluded and stated that 24 hours of staining invitro corresponds to approximately one month invivo, so specimens of this work were assessed after of 28 days (four weeks) of immersion, in order to equal two and half years of clinical immersion in staining solutions approximately. ${ }^{1}$

Instrumental color change measuring methods as spectrophotometers and colorimeters are used for assessement, with elimination of individual variation that occurs with visual color comparisons. They also made it more easy to study the different variables that may affect color stability. (CIE) L*a*b*; The Commission Internationale de l'Eclairage is a color system that is related to the color perception of the human eye. It is nearly a uniform color space which coordinates for lightness; white-black $\left(\mathrm{L}^{*}\right)$, red-green $\left(a^{*}\right)$, and yellow-blue $\left(b^{*}\right)$. Color change $(\Delta \mathrm{E})$ is a mathematical expression of the amount of difference between the $\mathrm{L}^{*} \mathrm{a}^{*} \mathrm{~b} *$ coordinates of different specimens or the same specimen at different situations ( $\Delta \mathrm{E}$ value presents relative color differences of dental materials or tooth surfaces before and after an intervention), so the CIELAB color system was chosen for the color assessment in this study. Also this system is a standard method for measuring color differences based on human perception; it was reported that changes in color values: $\Delta \mathrm{E}<1$ were undetectable by the human eye; $1.0<\Delta \mathrm{E}<3.3$ was appreciated only by a skilled person and considered clinically acceptable; whereas $\Delta \mathrm{E}>3.3$ was considered easily observed and not clinically acceptable. ${ }^{2}$ 
In this study significant differences in $\Delta \mathrm{E}$ values were found with the different thicknesses of bulk-fill resin composite with different immersion solutions as shown in table 4 , this finding was the same in two previous investigations by Ertas et al. ${ }^{8}$ and Villalta et al. ${ }^{9}$, resin composite specimens immersed in coffee produced the highest color change values when compared with the specimens of cola and distilled water, this was because when specimens were immersed in coffee, discoloration occurred due to both the adsorption and the absorption of pigments into the organic phase of resin-based materials. Coffee also contains significant amounts of staining agents such as gallic acid, which facilitate staining. ${ }^{2}$ In this study and in many previous ones, coffee has been found to be a stronger chromatogen than cola, this might be due to the fact that the yellow colorants of coffee are less polar than the yellow colorants of cola and since colorant polarity can determine the staining material degree of penetration into resinous materials; less polar colorants can be easily absorbed inside a resinous material, while more polar colorants tend to be only adsorbed on the surface of the material, coffee produced higher $\Delta \mathrm{E}$ values than cola with both thicknesses of resin composite. Also probably yellow colorants of coffee showed compatibility with the composite polymer phase matrix. ${ }^{10}$

Regarding color change in cola, it should be noted that cola gains its color due to the presence of caramel color in its composition, and that what caused change in color after Coca-Cola immersion. Color change could be also attributed to the roughness of the specimens that occurred due to the low pH (2.62) of the Coca-Cola solution, surely this roughness aided in the adsorption of the caramel color on the resin surface. These previous findings were in agreement with Patel et al. ${ }^{11}$ who stated that Coca-Cola causes color change of resin composites. ${ }^{4}$

The findings of our study revealed that immersion in distilled water also lead to slight discoloration. The degree of water absorption and the hydrophilic/hydrophobic nature of the resin matrix were the causes of the staining susceptibility of resin specimens. As it is well known that water absorption occurs mainly by the resin matrix, also excessive water absorption can decrease the life of resinous material by plasticizing and expanding its resin component. This will subsequently lead to microcracks or interfacial gaps at the interface between the filler and matrix and will allow stain penetration and discoloration. Furthermore it is postulated that the difference in the refractive index of filler and matrix of resinous materials increases after water absorption, allowing even more discoloration after water immersion. ${ }^{2}$

When it came to the behavior of the resin composite material itself (table 5) our results revealed that bulk-fill resin composite specimens with $2 \mathrm{~mm}$ thickness showed greater discoloration than the $4 \mathrm{~mm}$ thick specimens with both cola and coffee. The reason of this was based upon: the polymerization process of the resin, and the depth of cure which is the material's capacity to transfer light into its depths. A previous study by Flury et al. ${ }^{12}$ showed also that bulk-fill technique with specimens of $4 \mathrm{~mm}$ thickness resulted in a greater number of particle/resin matrix interfaces and increased light scattering due to the differences in their refractive indices, and lesser amount of photons reached deeper layers of the material and so a lower depth of cure was obtained at the deepest depths. Another study by Janda et al reported that with bulk fill the lower degree of conversion,affected the uncured monomer released and influenced the resin composite discoloration ${ }^{13}$. As a result of all previous statements the mechanical properties of bulk-fill resin composite material will deteriorate leading to greater residual monomer, more water absorption and more discoloration. ${ }^{2}$

Regarding the color stability of both ceramic materials presented in table 2 ; the results of this 
study revealed that, after immersion in cola and coffee, bulkfill resin composite with both thicknesses showed higher median $\Delta E$ values compared to both ceramic materials (table 5). This was in agreement with several studies that have been conducted to evaluate the color stability of dental restorations, and it has been concluded in all of them that resin composites are unable to retain the color they had possessed at the time of immersion in staining solutions and that the most common solutions that cause extrinsic stains are cola, tea, coffee, orange juice, and acidic beverages. ${ }^{14}$

Vita Enamic and Vitablocs Mark II revealed clinically acceptable color change values following immersion in cola and coffee when compared to bulk-fill resin composite. $\Delta E$ values listed in Table 5 showed that Vita Mark II had superior color stability compared to Vita Enamic following immersion in distilled water, but no significant difference in $\Delta E$ values was detected between both ceramics after immersion in both cola and coffee.

With coffee Vita Enamic showed higher $\Delta E$ values than Vita Mark II, since discoloration occurs as a result of water sorption by the resin component of the material. The type of resin matrix also plays an important role in the color sustainability of the material. Vita Enamic contains 14 wt \% Methacrylate polymer 66 wt \% hydrophobic urethane dimethacrylate (UDMA), and 33 wt \% hydrophilic triethylene glycol dimethacrylate (TEGDMA) leading to less color stability with the less polar coffee. As the proportion of TEGDMA increases from 0 to $1 \%$, the water uptake by resins increases from 3 to $6 \%$, and so the high wt $\%$ of TEGDMA in Vita Enamic resulted in increased water sorption and permission of penetration of hydrophilic colorants. On the other hand UDMA is more hydrophobic and therefore more color stable, nevertheless, dimethacrylates form cross-linked networks and entrap unreacted monomers that serve as plasticizers that forms an open structure, and facilitate additional water sorption. All the previous explained the higher discoloration values obtained by Vita Enamic ${ }^{15,16}$.

On the other hand, also no significant difference between $\Delta E$ values of the two materials existed after immersed in cola, although Vita Enamic showed lower $\Delta E$ values than Vita Mark II with cola, this might be attributed to the fact that the cola is a more polar dye in contrast to the less polar yellow colorant of the coffee, and so caramel dye penetration into the resin part of Vita Enamic has been more difficult, and the discoloration of Vita Enamic specimens with cola was extrinsic in nature and therefore, this discoloration might have been easily removed after the specimens were rinsed and wiped. When it came to the overall color stability of the two ceramic materials under all immersion solutions (table 4), Vita Enamic was less stable due to its Polymer-infiltrated nature in comparison to the pure feldspathic Vita Mark II, both were clinically acceptable and more color stable compared to bulkfill resin composite.

\section{CONCLUSION}

Within the limitations of this study, it can be concluded that resin composites are unable to retain their color after immersion and storage, but the color of both types of ceramic is stable even after immersion and storage in distilled water, cola and coffee.

\section{REFERENCES}

1. Saba DA, Salama RA, Haridy R. Effect of different beverages on the color stability and microhardness of CAD/CAM hybrid versus feldspathic ceramic blocks: An in-vitro study. Futur Dent J. 2017;3(2):61-66. doi:10.1016/j.fdj.2017.07.001

2. Shamszadeh S, Sheikh-Al-Eslamian SM, Hasani E, Abrandabadi AN, Panahandeh N. Color stability of the bulk-fill composite resins with different thickness in response to coffee/water immersion. Int J Dent. 2016;2016. doi:10.1155/2016/7186140 
3. VITA ENAMIC AG. VITA ENAMIC- Scientific Documentation. 2016;(08).

4. Kumari RV, Nagaraj H, Siddaraju K, Poluri RK. Evaluation of the Effect of Surface Polishing, Oral Beverages and Food Colorants on Color Stability and Surface Roughness of Nanocomposite Resins. J Int oral Heal JIOH. 2015;7(7):63-70.

5. Nuaimi H, Garg P. Color Stability of Nano Resin Based Composite With Novel Monomer After THREE MONTHS STORING. International Journal of Dental and Health Sciences.2014; 1(2):112-120.01(02).

6. Ribeiro JS, Peralta SL, Salgado VE, Lund RG. In situ evaluation of color stability and hardness' decrease of resinbased composites. J Esthet Restor Dent. 2017;29(5):356361. doi:10.1111/jerd.12319

7. Yildiz E, Sirin Karaarslan E, Simsek M, Ozsevik AS, Usumez A. Color stability and surface roughness of polished anterior restorative materials. Dent Mater J. 2015;34(5):629-639. doi:10.4012/dmj.2014-344

8. Ertaş E, Güler AU, Yücel AÇ, Köprülü H, Güler E. Color stability of resin composites after immersion in different drinks. Dent Mater J. 2006;25(2):371-376. doi:10.4012/ dmj.25.371

9. Villalta P, Lu H, Okte Z, Garcia-Godoy F, Powers JM. Effects of staining and bleaching on color change of dental composite resins. J Prosthet Dent. 2006;95(2):137-142. doi:10.1016/j.prosdent.2005.11.019

10. Polli M, Arossi G. Effect of finishing and polishing on the color stability of a composite resin immersed in staining so- lutions. J Dent Res Rev. 2015;2(3):120. doi:10.4103/23482915.169825

11. Patel SB, Gordan V V., Barrett AA, Shen C. The effect of surface finishing and storage solutions on the color stability of resin-based composites. J Am Dent Assoc. 2004;135(5):587-594. doi:10.14219/jada.archive. 2004.0246

12. Flury S, Hayoz S, Peutzfeldt A, Hüsler J, Lussi A. Depth of cure of resin composites: Is the ISO 4049 method suitable for bulk fill materials? Dent Mater. 2012;28(5):521528. doi:10.1016/j.dental.2012.02.002

13. Janda R, Roulet JF, Kaminsky M, Steffin G, Latta M. Color stability of resin matrix restorative materials as a function of the method of light activation. Eur J Oral Sci. 2004;112(3):280285. doi:10.1111/j.1600-0722.2004.00125.x

14. Prajapati AM, Sanyal PK, Guru R, Vaswani P, Tewary S, Sushma R. Effect of Tobacco Extract, Cigarette Smoke, and Carbonated Beverage on Surface Roughness and Color Stability of Three different Restorative Materials: An in vitro Study. Int J Prev Clin Dent Res. 2017;4(1):9-18. doi:10.5005/jp-journals-10052-0073

15. Acar O, Yilmaz B, Altintas SH, Chandrasekaran I JW. Color stainability of CAD_CAM and nanocomposite resin materials.J Prosthet Dent. 2016 Jan;115(1):71-5.

16. De Alencar e Silva Leite ML, Da Cunha Medeiros e Silva FDS, Meireles SS, Duarte RM, Maciel Andrade AK. The effect of drinks on color stability and surface roughness of nanocomposites. Eur J Dent. 2014;8(3):330-336. doi:10.4103/1305-7456.13764 